\title{
THE FACTORS INFLUENCING BOTTLE FEEDING AMONG THE MOTHERS OF THE CHILDREN AGED BETWEEN 6 MONTHS AND 2 YEARS
}

\author{
*Ms. Soniya Chacko \& **Prof. P. Chitra
}

\section{Introduction}

The feeding bottle, the tiny plastic container that has been viewed as a readymade solution, to most of the mothers, to soothe a wailing baby is seen, alarmingly, as an enemy. The Infant Milk Substitutes, Feeding Bottles and Infant Foods (Regulation of Production, Supply and Distribution) Act, 1992 prohibits the promotion of feeding bottles. Medical articles by the Indian Academy of Paediatrics (IAP) have linked inappropriate methods of feeding infants to mortality and morbidity of infants. The risk of infection is high as the micro-organisms may stick to the neck and teat of the bottle and get transmitted to the infant, if the bottle is reused. Bottle feeding is one of the major causes of diarrhea among the infants. The rate of bottlefeeding practice keeps on increasing among the mothers with infants older than four months due to early weaning. The major reasons for bottlefeeding practice include insufficient breast milk, the need to go back to work and the use of contraceptive pills.

\section{Statement of the problem}

"A study on the factors influencing bottle feeding among the mothers of the children aged between 6 months and 2 years in selected pediatric departments at AIMS, Kochi."

\section{Objectives of the study}

1.To identify the feeding practices among the mothers of children aged between 6 months and 2 years.

2.To find the factors influencing the practice of bottle feeding among the mothers of the children aged between 6 months and 2 years.

3.To find the association between the practice of bottle feeding, among the mothers of the children aged between 6 months and 2 years, and the selected demographic variables.

\section{Research methodology}

A non-experimental quantitative research approach was used for the study. The research design selected for the present study was descriptive study. The sample was selected using the convenience sampling method. A sample, of 100 mothers, was selected from the Pediatric Medical and Surgical Out Patient Departments. The Mothers of the children, aged between 6 months and 2 years, were included in the study and the mothers who have critically- ill children were excluded.

\section{Tool for the study}

The data collection tool was developed by the investigators. A semi-structured questionnaire was used to identify the feeding practices among the mothers. A cafeteria questionnaire was used to find the factors influencing bottle feeding practice which contains 6 factors and 5 items under each factor. The factors, considered, were biological, psychological, educational, socio-economic, environmental and cultural.

\section{Data analysis}

The data were analyzed using descriptive and inferential statistics.

\section{Results}

a) Identifying the feeding practices among the mothers of the children aged between 6

\section{*II year M.Sc. Nursing \& **Professor. Child Health Nursing,AIMS, Kerala.pchitraaims@amrita.edu}


months and 2 years.

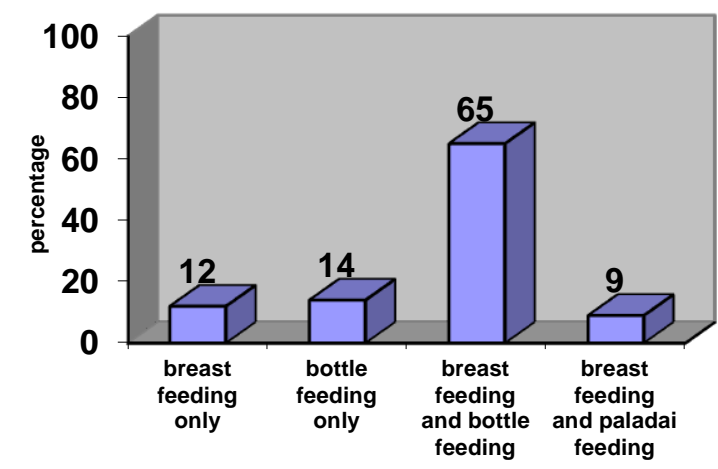

b) Factors influencing bottle feeding practices in children

1. Biological factors (inadequate production of milk).

2. Psychological factors (breast milk does not fulfill all the requirements of the infants).

3. Educational factors (belief that if the bottle is cleansed properly, it will not cause any Disease).

4. Socio-economic factors (choosing bottle feeding for the need to go back to work).

5. Environmental factors (separation from the infants for a longer period of time cause difficulty to breast feed).

6. Cultural factors (mother/grandmothers decision to give breast milk only upto 3 months).

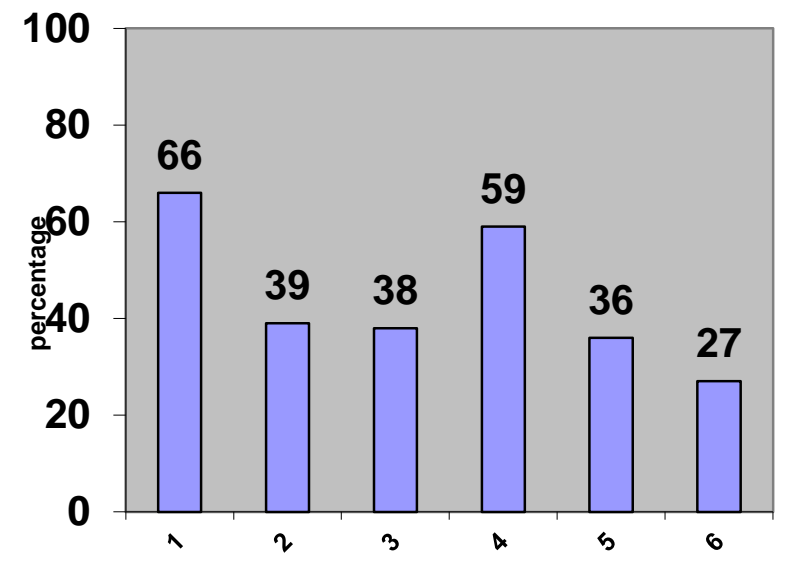

The other factors influencing bottle feeding are recurrent hospitalization of the child with $36(46 \%)$ mothers, the need to go for higher education with 17 (22) mothers and inevitable absence of the mothers, numbering 10 (13\%).

There is a significant association between bottle feeding practice and the age of the mother, working nature of the mothers and the weight of the child.

Among the 79 subjects, 49 (62\%) children have recurrent episodes of diarrhea, 41 $(52 \%)$ have recurrent ear infections, most of the children are overweight, and 44 (100\%) follow the practicing bottle feeding.

\section{Discussion}

Lukman, $\mathrm{H}$ et al. conducted a crosssectional analytical study on the factors influencing bottle-feeding practice among the infants at the Well-Child Clinic of Dr. Pirngadi Hospital, Medan. Among the 85 infants aged 0-3 months, 10 infants (11.7\%) were exclusively bottle-fed, 35 (41.2\%) bottle- and breast fed and 40 (47.1\%), exclusively, were breast-fed. Among the 85 infants aged 7-12 months, 28 (32.9\%) were bottle-fed, 29 (34.2\%) were breast and bottle-fed, and 28 (32.9\%) were breast-fed. The result of review shows the fact that 29 (34.2\%) infants were breast and bottle-fed. But the present study findings identify 65(65\%) mothers as practicing breast feeding along with bottle feeding which shows the fact that the practice of bottle feeding seems to be increasing in our society.

Dr. Abdul Kareem J Mohammad, et al. conducted a study in 3 Public Health Centers and Teaching Hospital in Baghdad city. The Mothers were interviewed to collect information on the practice of breast or bottle feeding and the 
causes of using bottle feeding. A total of 2008 mothers were included, in this study, and 28 of them used bottle feeding which constituting $63.8 \%$, a statistically significant value. The researchers found the causes, that lead to the increase in the percentage of bottle feeding ; namely inadequacy of breast milk with $72.4 \%$ subjects, underwent caesarian section in the case of $8.6 \%$, on the physician's advice with $3.5 \%$, personal decision with $2.8 \%$, other causes with $1.9 \%$, and the use of drugs in the case of $0.8 \%$ subjects.

\section{Conclusion}

The Indian Medical Association Society Act, 2003 prohibits the promotion of feeding bottles. But majority of the mothers use bottle feeding since they are not aware of the hazards of the bottle feeding. The hazards of bottle feeding needs to be studied thoroughly and, neglecting these will potentially affect the health of the babies. Nurses play a major role in educating the mothers about the adverse effects of bottle feeding. The researcher recommends the need for the mothers to get educated on the ill-effects of bottle feeding and be aware of the truth that the practice of bottle feeding can cause diseases to the children. This objective can be achieved through health education programs about the importance of breast feeding and the health professionals should educate the mothers about the disadvantages of bottle feeding and pay more attention in the promotion of breast feeding using the mass media as the strategy.

\section{References}

Marilyn J Hockenberry (2006). Wong's Essentials of Pediatric Nursing, $7^{\text {th }}$ edition, Elsevier Publishers, page no:205.
Food Nutrition Bulletin. (2010) Jun;31(2):31433 Infant and young child feeding indicators and determinants of poor feeding practices in India: secondary data analysis of National Family Health Survey 2005-06.

Olympia Shilpa Gerald (2012). The Hindu, Health Policies\& issues: Bottles, not the best way to feed your baby,TIRUCHI, August 10.

Jane Brotanek, (2000) Prolonged Bottle-Feeding Can Lead to Iron Deficiency in Toddlers, Pediatrics for Parents.

Hamdiya AS Al-Fadli, Layla Al-Jasem, Abdul Hameed A, Al-Jady, Gamal M Masoud(2006). Factors Underlying Bottle-feeding Practice in Kuwait (2001),Kuwait Medical Journal, 38 (2): 118-121

Ojo M Agunbiade and Opeyemi V Ogunleye (2012).Constraints to exclusive breastfeeding practice among breastfeeding mothers in Southwest Nigeria: implications for scaling up International Breastfeeding Journal, 7:5

Mathews K, Maternal. infant-feeding decisions: reasons and influences.Canadian Journal Nursing Research.Summer;30(2):177-98

Breast feeding, April 2012.Available from wikipedia.org/wiki/Breastfeeding

Diane M. Fraser, Margaret A. Cooper (2003). Myles Textbook for Midwives, $14^{\text {th }}$ edition. pp:752-753. 